\title{
KAJIAN KONSERVASI TRADISIONAL MENURUT NASKAH KUNO
}

\author{
Isni Wahyuningsih, Sri Sularsih, Siti Yuanisa, Dimas Arif Primanda Aji \\ Balai Konservasi Borobudur \\ Email : isni.wahyuningsih@gmail.com
}

\begin{abstract}
Abstrak : Konservasi tradisional dapat diketahui baik secara lisan dan maupun tulisan. Secara lisan dilakukan turun temurun, sedangkan secara tulisan terdapat dalam naskah-naskah kuno. Kajian Konservasi Tradisional Menurut Naskah Kuno bertujuan untuk menelusuri keberadaan bahan, alat, ataupun metode konservasi tradisional yang tercatat dalam naskah kuno dan mengilmiahkannya. Kajian ini diharapkan dapat diterapkan dalam upaya pelestarian cagar budaya dan melestarikan budaya tulis itu sendiri.

Pada naskah-naskah kuno di Jawa yang berupa suluk, primbon maupun serat tidak dijumpai pengawetan suatu benda dalam hal pascapembuatan. Namun memuat cara membuat awet suatu benda atau bangunan (konservasi secara alami) pada proses pembuatannya yang didasarkan pada pemilihan bahan, perlakuan terhadap bahan, dan waktu pembuatan.
\end{abstract}

Kata Kunci: Naskah kuno, konservasi, tradisional

Abstract : Traditional conservation techniques are preserved through oral and written history. Orally it is performed through storytelling over generation while on the other had the techniques could be recorded in ancient texts. Study on Traditional Conservation based on Ancient Texts is aimed to document the materials, tools, and methods included in the texts and to study them in modern scientific methodology. This study is as much about practical heritage conservation as preservation of writing culture.

It turns out that Javanese texts such as suluk, primbon and serat do not give instruction on preserving an object after it was made. Nonetheless, there are many methods used in the construction of an object or building, through natural environment, that would make it last longer by selecting suitable materials, using best treatments and appropriate length of construction.

Keyword : Ancient Texts, conservation, Traditional

\section{PENDAHULUAN}

\subsection{Latar Belakang}

Konservasi dalam kamus besar bahasa Indonesia mempunyai arti pemeliharaan dan perlindungan sesuatu secara teratur untuk mencegah kerusakan dan kemusnahan dengan jalan mengawetkan; pengawetan; pelestarian (KBBI). Adapun istilah konservasi dalam kaitannya dengan upaya pelestarian material cagar budaya adalah serangkaian tindakan perawatan benda, bangunan, struktur dan atau komponen bangunan yang menitikberatkan pada upaya pembersihan, pengawetan dengan tujuan agar bisa bertahan lebih lama. Sementara itu istilah konservasi tradisional adalah tindakan konservasi yang menggunakan bahan dan peralatan tradisional, yang berpatokan pada local wisdom (kearifan lokal) serta pengalaman yang yang terakumulasi dalam pengetahuan masyarakat setempat (people knowledge). Praktek konservasi tradisional di dalamnya mengandung unsur bahan tradisonal dan peralatan tradisional. Bahan tradisional adalah bahan yang diperoleh dari lingkungan setempat atas dasar pengalaman turun temurun. Sementara peralatan tradisional adalah peralatan sederhana yang dibuat masyarakat dengan bahan yang diperoleh dari lingkungannya. Bahan serta peralatan konservasi tersebut yang menjadi pembeda antara konservasi tradisional dan konservasi modern. (Sunarno dalam Swastikawati, 2015).

Konservasi tradisional dapat diketahui baik secara lisan dan telah dilakukan turun temurun maupun tulisan yang dimuat dalam naskahnaskah kuno. Naskah kuno merupakan warisan budaya tertulis karya masyarakat tradisional di masa lampau yang merekam berbagai aspek kehidupan. Naskah kuno juga sebagai bukti hasil 
kegiatan intelektual masyarakat tradisional di masa lampau dalam memecahkan permasalahan dalam kehidupan (local genius) antara lain dalam hal konservasi (Susena, 2013). Indonesia kaya akan khazanah warisan budaya tertulis dalam bentuk naskah (manuskrip) yang berjumlah ribuan yang tersimpan di dalam negeri maupun di luar negeri, dimiliki oleh pemerintah maupun milik pribadi. Di Pulau Jawa biasanya naskah kuno disebut serat, suluk atau primbon yang kebanyakan di dalamnya memuat ajaran dalam kehidupan.

Untuk mengetahui konservasi tradisional yang telah dilakukan nenek moyang pada masa lampau maka diperlukan Kajian Konservasi Tradisional Menurut Naskah Kuno. Kajian tersebut bertujuan untuk menelusuri keberadaan bahan, alat, ataupun metode konservasi tradisional yang tercatat dalam naskah kuno. Kajian tersebut diharapkan dapat diterapkan dalam upaya pelestarian cagar budaya, sekaligus melestarikan budaya (konservasi tradisional yang dimuat dalam naskah kuno).

\subsection{Rumusan Masalah}

Berdasarkan uraian di atas maka dapat dikemukakan rumusan masalah sebagai berikut.

Bagaimanakah praktek-praktek konservasi yang termuat dalam naskah-naskah kuno?

\subsection{Tujuan Penelitian}

Adapun tujuan dari kajian tersebut adalah sebagai berikut

1. Menelusuri untuk mengetahui keberadaan praktek-praktek konservasi tradisional yang dahulu dilakukan oleh nenek moyang berdasarkan teks yang tertulis pada naskahnaskah kuno.

2. Mengilmiahkan keberadaan praktek konservasi tradisional sehingga dapat diterapkan dalam upaya pelestarian cagar budaya.

3. Melestarikan keberadaan konservasi tradisional yang telah dilakukan nenek moyang yang dimuat dalam naskah kuno.

\subsection{Manfaat Penelitian}

Manfaat dari kajian Konservasi Tradisional Menurut Naskah Kuno adalah terlestarikannya konservasi tradisional yang terekam dalam tradisi tulis yang ada dalam naskah kuno.

\section{TINJAUAN PUSTAKA}

Upaya penerapan kembali konservasi tradisional dalam pelestarian cagar budaya telah mulai dilakukan, begitu upaya untuk mengilmiahkan bahan konservan tradisional tersebut. Salah satunya telah dilakukan oleh Swastikawati (2011-2014) yang telah melakukan kajian konservasi cagar budaya berbahan logam menggunakan metode konservasi tradisional dengan bahan-bahan alami. Metode tradisional yang diterapkan dalam kajian tersebut didasari dari tradisi lisan yang masih dijumpai dan dilakukan oleh masyarakat sekitar, seperti penjamasan keris dengan menggunakan jeruk nipis. Sementara itu untuk kajian konservasi tradisional yang dirujuk berdasarkan budaya tulis atau teks yang berupa naskah kuno belum pernah dilakukan. Kajian-kajian yang telah dilakukan yang merujuk pada naskah kuno antara lain adalah ilmu pengobatan (Susena, 2013; Kasrina, 2015)

\section{METODE PENELITIAN}

\subsection{Ruang Lingkup Kajian}

Ruang lingkup dari Kajian Konservasi Menurut Naskah Kuno adalah naskah-naskah kuno yang merupakan hasil karya para pujangga pada masa kerajaan-kerajaan di Jawa, dengan batasan rentang waktu abad ke 15 - 19.

\subsection{Pengumpulan Data}

Pengumpulan data dalam penelitian tersebut menggunakan langkah sebagai berikut.

a. Melakukan penelusuran terhadap naskahnaskah kuno yang di dalamnya memuat atau mengandung unsur konservasi tradisional.

b. Wawancara dilakukan dengan narasumber ataupun tokoh yang memahami naskahnaskah kuno. 
c. Pengumpulan data sekunder dilakukan dengan pengumpulan data literatur dan studi-studi terdahulu terkait dengan penelitian.

\subsection{Metode Penelitian}

Metode penelitian yaang dilakukan dalam kajian ini menggunakan langkah-langkah sebagai berikut.

1. Metode telaah kepustakaan dan kritik teks. Secara teknis, dalam upaya pengumpulan data dalam kajian ini dilakukan pengumpulan naskah yang diteliti, penerjemahan, wawancara, dan kritik teks yaitu memberi evaluasi, menempatkan teks sewajarnya serta mengkaji lembaran naskah yang kemungkinan mengandung muatan konservasi tradisional. Setelah itu dijelaskan kembali sehingga bisa diterima atau dipahami secara umum.

2. Metode analogi etnografi, merupakan analisis yang digunakan untuk membandingkan bahan, alat, dan metode konservasi tradisional yang termuat dalam naskah kuno dengan kondisi konservasi tradisonal yang masih bisa dijumpai di masyarakat pada saat ini.

3. Kesimpulan ditarik dari hasil analisis

\section{KONSERVASI TRADISIONAL YANG ADA DALAM NASKAH KUNO}

\subsection{Data Naskah Kuno}

Pencarian data untuk Kajian Konservasi Berdasarkan Tinjauan Naskah Kuno adalah dengan melakukan penelusuran naskah kuno yang tersimpan di UGM, Museum Sonobudoyo, ANRI, Perpustakaan Nasional, dan Museum Nasional. Dalam upaya pengumpulan data diambil dalam katalog naskah kuno yang berbahasa dan bertulis Jawa Kuno ataupun yang sudah diterjemahkan. Untuk mempermudah penelusuran di beberapa tempat tersebut di atas dengan melihat katalog, ataupun database yang diperkirakan dari judul berhubungan dengan kajian.
Dalam kajian ini diambil sejumlah sampel judul naskah berupa naskah primbon, suluk dan serat yang mengandung unsur konservasi.

\subsection{Unsur Konservasi Tradisional Dalam Naskah} Kuno

3.3. Setelah dilakukan telaah atas sampel naskah tersebut dijumpai beberapa kesamaan - kesamaan atas isi dari beberapa naskah baik itu di dalam naskah primbon, suluk dan serat. Data yang termuat dalam naskah kuno dapat dikaitkan dengan konservasi sebagai berikut.

a. Teks yang memuat mengenai pemilihan kayu, tata cara penebangan pohon, perlakuan terhadap kayu yang digunakan untuk pembuatan rumah atau perabotan termuat dalam Serat Centhini, Kawruh Griyo, Kawruh Kalang, Primbon, dan Seserepan Griyo, yang cuplikannya sebagai berikut.

"Griya sela wau inggil-inggilanipun prayogi kasantunan kajeng jati utawi kajeng sanesipun. Milanipun makaten supados entheng mboten mutawadosi kados sela, saha gampil panggarapipun, amargi manawi sela punika anjing-anjingipun katurut ing toya jawah. Lami-lami rimpil andadosaken risak.

Pamilibing kajeng jati ingkang empuk serta ingkang atos. Kajeng jati ingkang saget ageng sarta kathah, punika thuk.ul wonten ing pareden tuwin wana, ingkang sitinipun abrit utawi cemeng. Kajeng jati ingkang thukul wonten siti abrit, dhasar atos, serat rentet, alus anglisah, ingkang thukul wonten ing siti cemeng, dhasar empuk. serat gopok utawi mrupuk, ngendhal kados pulut.

Nadyan nunggil pasitenipun mawi undha usuk tigang pangkat :

1. Jati Bang = dhasar atos, alus, anglisah, kangge dandosan awet.

2. Jati Kembang utawi sungu= dhasar cemeng, serat ler-leran kados sekar utawi kados sungu. Kangge dandosan awet, nanging mboten saget ngungkuli awetipun Jati Bang

3. Jati Kapur = dhasar empuk serat mrupuk utawi gopok. Wujudipun pethak kusi. Kangge dandosan kirang awet. 
Katrangan anegor sarta ndamel gebingan tuwin sirap.

Anegor kajeng jati ingkang sae anggenipun punika kedah kateres rumiyin. Teres punika poking uwit kintel 3 utawi 4 kaki saking siti. Kabacok ing wadung mubeng temu gelang, wiwit kulit dumugi ingkang sampun warni abrit. Godhong lajeng sami gogrog saha lajeng anggalinggang. Manawi sampun sataun saking paneresipun sampun kenging kategor, margi sampun garing, wantek mboten angubet.

Rebahing kajeng ingkang kategor wau kaangkah sageta rebah mangaler utawi mangidul, sarta sampun ngantos andhawahi kajeng ingkang taksih gesang, kasangsang, tumumpang tunggak, kantep, sapanunggilanipun ingkang dados tampikan kados bab saderingipun

Menggah pratikelipun supados sumerep dhawahipun pucuking kajeng ingkang badhe karebahaken punika kedah nangguh wanci enjing utawi sonten ingkang wayanganipun wujud sami kaliyan panjangipun. Umpami balebes ingkang panjangipun 5 kaki. Dipun degaken, mangka wayanganipun ugi 5 kaki. Punika wayanganipun kajeng ingkeang badhe karebahaken wau kaukura. Sapinten panjanging wayanganipun inggih punika badhe ukuranipun dhawahing pucukipun. Pratikel ingkang makaten wau ugi tumrap kaangge napsir panjang celakipun kajeng ingkang badhe kangge dandosan. Kados umpami badhe ngangge saka ingkang panjangipun 20 kaki, manawi wayanganipun kajeng kados ing nginggil wau wonten utawi langkung 20 kaki, inggih badhe saget cekap kaangge saka ingkang panjangipun 20 kaki wau. Wondene panaksir agengipun pucuking kajeng punika kenging kapirid saking agenging bongkotipun.

Menggah pangangkahipun supados dhawabing kajeng saget prayogi rebahipun, punika kedah kadhawahaken selaning kajeng ingkang gesang. Nanging kasrampataken ing pang alit-alit, supados sampun ngantos remuk utawi getem saking dhawah kantep. Sasampunipun rebah lajeng kaprejeng utawi karimbas 2 wadana, ngiras ngupadosi manabing kajeng.

Manawi sampun kapanggih manahipun kajeng kakethok miturut manahipun kajeng, lajeng kasipat kadamel pasagi. Ing bongkot kagembes. Sasampuning dados gebingan utawi balok lajeng kenging kangge dandosan griya. Menggah pangangkah manabing kajeng wau ingkang sae piyambak manah kabucal. Kawastanan kajeng bethetan. Madyanipun manah wonten tengah urut, ingkang asor manah menggak-menggok wonten tengah akaliyan pinggir.

Wondene kajeng kocoran inggih punika kajeng gesang ingkang lajeng kategor mboten mawi kateres rumiyin.
Sasampunipun dados gebingan lajeng dipun kentheng kagambang kados galar kareteg dipun ganjel inggil kados amben wonten panggenan banar. Laminipun $e$ wulan manginggil, manawi kajeng badhe baita, wuwung, sapanunggilipun pangenthengipun wonten panggenan ingkang asrep utawi eyup, laminipun ugi 3 wulan manginggil.

Kajeng ingkang kadamel sirap teresan ingkang burus. Manawi tiyang alit utawi bangsa andhap purun damel sirap saking glinggang, sarta brokah. Manawi pundhutaning ratu utawi bangsa luhur, kedah negor saking teresan, utawi negor kajeng ingkang taksih gesang. Pilihanipun ingkang burus.

Patrap panyigaripun sasampuning kajeng rebah, kapilih ingkang burus tanpa cacat. Sasisib dipun gethake sapanjangipun ukuraning sirap dipun pancas ngiras kadamel lancur. Gethakan wau kaanjingan /240/ paju, lajeng kagandhen. Dene pajunipun kapara kathah. Manawi sampun dados balebekan lajeng karimbas kacalonan wangun sirap, nanging taksih kandel. Dipun kendelaken 3 wulan manginggil. Lajeng kapacak dados. Manawi katututan manah kabucal mboten kangge, margi watakipun kisut, ngulet utawi mandhelong.

Manawi kajeng kocoran patraping panggarap ugi kados nginggil wau, nanging panglerepipun rambah kaping kalih. Sasampuning lerep sapisan karimbas kaalitaken. Lajeng kalerepaken malih, laminipun ugi 3 wulan manginggil. Manawi kirang dangu panglerepipun badhe ngulet, mandhelong, ngliwa utawi ngelo, remuk enggal trocoh.

b. Teks yang memuat tentang terkait dengan persenjataan yang terbuat dari logam seperti keris atau tombak juga lebih mengungkapkan proses memilih bahan, jenis-jenis logam, dan cara pembuatan keris atau tombak seperti yang termuat dalam Kawruh Keris.

c. Teks yang memuat beberapa bahan yang dapat membunuh hewan sejenis serangga (ulat, lintah atau rena) yang disebut "minyak latung" dapat membunuh hewan tersebut serta daun rembega (widuri) disebutkan dapat membunuh ulat kecil-kecil termuat dalam Serat Primbon Jampi Jawi.

\subsection{Pembahasan}

Dalam naskah-naskah kuno di Jawa yang dijadikan sampel pada kajian ini, setelah ditelaah tidak dijumpai teks yang memuat konservasi secara lugas dan jelas, namun menyebutkan perawatan atau pengawetan suatu benda secara detail mengenai alat, cara, dan bahan pengawet (pasca pembuatan/ proses pemakaian suatu benda). Hal tersebut dipahami 
berdasarkan pola pikir pada zaman tersebut belum ada suatu pemikiran untuk menulis secara jelas dan terperinci hal-hal yang terkait memelihara, merawat suatu mengawetkan suatu benda yang telah mereka buat, karena benda tersebut masih ada dan kalaupun rusak bisa dibuat lagi.

Dalam arkeologi sebagai ilmu yang didalamnya adalah untuk mengetahui aspek perilaku manusia masa lampau melalui jejak-jejak yang ditinggalkan, baik berupa benda, berbentuk alat atau bukan bukan alat. Perilaku manusia yang telah menghasilkan tinggalan arkeologis mencakup 3 hal, yaitu: buat pakai - buang (Sharer and Ashmore, 1977). Hal yang bersangkutan dengan proses buat dan pakai terhadap benda atau artefak akan terbentuk polah tingkah laku. Perlakuan yang dialami oleh suatu artefak dari saat dibuat hingga ditemukan oleh manusia masa kini, termasuk seluruh rangkaian prosesnya. Selanjutnya hal tersebut menjadi proses pembentukan budaya (Schiffer, 1976). Perlakuan terhadap suatu benda yang dibuat oleh manusia menghasilkan budaya tingkah laku yang mengandung kearifan lokal, termasuk didalamnya upaya masyarakat dalam proses membuat dan merawat selama pemakaian suatu benda. Dalam naskah kuno yang dijadikan sampel tersebut memuat unsur dalam membuat suatu benda atau bangunan terlebih dahulu dipilih bahan dengan kualitas dan kualifikasi tertentu agar benda atau bangunan yang akan dibuat akan berkualitas baik, awet, dan waktu pembuatan akan membawa pengaruh kebaikan bagi penghuninya (kesatuan dengan alam) sebagai kearifan lokal.

Dalam cuplikan sampel naskah kuno di atas, dimuat hal tentang pemilihan kayu jati yang berkualitas dengan melihat di mana dan jenis tanah di mana pohon tersebut tumbuh. Walaupun pada tanah yang sama, kayu jati mempunyai tiga tingkatan:

1. Jati bang; pada dasarnya keras, halus, rapat berminyak, awet apabila digunakan untuk perabotan.

2. Jati kembang atau jati sungu; pada dasarnya hitam, serat hanya beberapa seperti bunga dan seperti tanduk, awet untuk perabotan, tetapi tidak bisa melebihi keawetan jati bang

3. Jati kapur, pada dasarnya lunak, serat lapuk, warna putih pucat bersisik-sisik, kurang awet apabila digunakan sebagai perabotan.

Dalam kepercayaan orang Jawa, pemilihan kayu jati mempunyai pengaruh baik dan buruk. Kayu jati yang dianggap mempunyai pengaruh baik itu dapat mendatangkan banyak rezeki, keselamatan, dan sebagainya. Pada saat menebang dan membelah pohon perlu diperhatikan cara/teknik dan waktunya, apalagi untuk membuat sirap, menebang kayu jati yang baik pada awalnya harus membuat alur sayatan pada pohon yang akan ditebang (neres: bahasa Jawa) terlebih dahulu. Neres, pangkal pohon kira-kira 3 atau 4 kaki dari tanah, ditebang dengan wadung (kampak) melingkar sampai bersinggungan dari kulitnya sampai pada bagian yang sudah berwarna merah. Setelah itu daun-daun rontok dan mengelupas dan sebaiknya dibiarkan 1 tahun. Setelah itu, pohon jati dapat ditebang karena sudah kering keras dan tidak berubah bentuk. Dalam menebang pohon arah jatuhnya kayu juga menjadi pertimbangan terutama ke arah utara. Tumbangnya pohon diusahakan jangan sampai merobohi pohon yang masih hidup, tersangkut, menumpang pohon lain. Adapun supaya jatuhnya ujung kayu yang kan dirobohkan harus menggunakan kesempatan baik pada waktu pagi atau sore hari. Ketika panjang bayangan bentuknya sama dengan panjang kayunya, untuk mengukur panjang kayu yang akan digunakan. Dalam menebang juga menggunakan teknik gethak atau pacal. Di-gethak adalah dipotong tapi tidak sampai putus, sedangkan di-pacal adalah pada bagian atau gethakean dibagi-bagi dikelupas atau menyobek tepat dengan gethakan tadi. Jika yang akan digunakan pohon yang masih hidup ditebang dan dibiarkan selama paling tidak tiga bulan dan diletakkan ditempat lebih tinggi, dengan amben (dipan) diganjal agar tidak langsung terkena tanah. Penebangan pohon juga menggunakan perhitungan waktu (titi mongso).

Beberapa bahan lain disebutkan dalam naskah kuno yang dapat dikaitkan dengan upaya konservasi tradisional, seperti dalam Serat Primbon Jampi Jawi 
tertulis beberapa bahan yang dapat membunuh ulat, lintah atau rena yang disebut " minyak latung” dapat membunuh hewan tersebut. Daun rembega/widuri/ biduri disebutkan dapat membunuh ulat kecil-kecil. Daun widuri yang disebutkan dapat membunuh ulat kecil-kecil diharapkan dapat diterapkan untuk mengusir ulat atau serangga yang ada benda seperti di kain, kertas atau kayu perlu untuk diuji coba.

Pengetahuan yang telah diturunkan oleh nenek moyang tersebut jika memungkinkan dapat digunakan untuk upaya konservasi tradisional, seperti penggantian bagian dari rumah tradisional yang rusak bila perlu menggunakan atau mempertimbangkan apa yang nenek moyang lakukan dalam proses pembuatannya agar selaras antara bahan asli dan bahan pengganti.

\section{DAFTAR PUSTAKA}

Almos, Rona \& Pramono, 2015. "Leksikon Etnomedisin Dalam Pengobatan Tradisional Minangkabau" dalam Jurnal Arbitrer Vol. 2 April 2015. Padang : Universitas Andalas.

Behrend, T. E, 1990. Katalog Induk Naskah-Naskah Nusantara Jilid I Museum Sonobudoyo. Jakarta: Djambatan

1997. Katalog Induk Naskah-Naskah Nusantara Jilid 3A Fakultas Sastra Universitas Indonesia. Jakarta : Yayasan Obor Indonesia 1997. Katalog Induk Naskah-Naskah Nusantara Jilid 3B Fakultas Sastra Universitas Indonesia. Jakarta : Yayasan Obor Indonesia -1997. Katalog Induk Naskah-Naskah

Nusantara Jilid 4 Perpustakaan Nasional Indonesia. Jakarta : Yayasan Obor Indonesia

Mulyana, Deddy, 2001. Metode Penelitian Kualitatif. Bandung : PT. Remaja Rusdakarya.

Lindsay Jennifer, Soetanto RM, dan Feinstein, Alan, 1994. Katalog Induk Naskah-Naskah Nusantara Jilid 2 Kraton Yogyakarta. Jakarta: Yayasan Obor Indonesia

\section{PENUTUP}

\subsection{Kesimpulan}

Dalam Kajian Konservasi Tradisional Menurut Naskah Kuno, sampel naskah kuno dari daerah Jawa berupa primbon, serat, dan suluk tidak dijumpai unsur teks yang memuat konservasi (pengawetan) yang spesifik. Disampaikan secara lugas dan jelas menyebut bahan, alat, cara atau metode dalam melakukan konservasi terhadap suatu benda (selama proses pemakaian). Namun yang dijumpai lebih cenderung pada teks yang memuat unsur membuat awet suatu benda atau bangunan (konservasi secara alami) pada proses pembuatannya yang didasarkan pada pemilihan bahan, perlakuan terhadap bahan, dan waktu pembuatan.

\subsection{Saran}

Perlu dilakukan uji laboratorium untuk mengilmiahkan konservasi yang telah dilakukan oleh nenek moyang moyang terkait dengan pemilihan bahan, perlakuan terhadap bahan serta bahan lain yang dapat digunakan sebagai konservan.

Susena, Danang, dkk, 2013. "Pengobatan Tradisional Dalam Naskah-naskah Minangkabau dalam WACANA ETNIK, Jurnal Ilmu Sosial dan Humaniora Vol. 4 No. 2 Oktober 2013. Hlm 13152.

Swastikawati, Ari, 2013. Metode Konservasi Tradisional Cagar Budaya Berbahan Logam. Magelang : Balai Konservasi Borobudur.

h t t p : / / t e gu him a n pras ojo. wordpres s. com/2008/08/09/25/etnografi 